accompanies these various approaches to changing the FDA. And Kessler is warning that there are limits to reform-necessary to ensure safety-beyond which the agency dare not go. But lately, although the bickering sometimes contains familiar politically inspired complaints, the breathlessness of the main participants seems to reflect the stepped-up tempo of the reform process itself.

Jeffrey L. Fox

\title{
Yeast: A sequence model, not a management one
}

With accompanying simultaneous press conferences in Brussels and Washington, the last of the data from the international Saccharomyces cerevisiae genome project was released on April 24. At 12.05 megabase pairs $(\mathrm{Mbp})$ of nonredundant sequence, yeast is the first eukaryote, and its 16-chromosome genome the largest genome, to be sequenced. This is a significant milestone for the genomics community. When André Goffeau from the Catholic University of Louvain (Louvain, Belgium), the prime mover behind the project, announced the completion of the sequencing work at the recent Human Genome Organization (HUGO) meeting in Heidelberg (March 22-24), the assembled geneticists clapped and cheered spontaneously.

The latest release is of $4 \mathrm{Mbp}$ of sequence as completed contigs of yeast chromosomes IV, VII, XII, XIV, XV, and XVI, but much of the data (around $90 \%$ of the yeast genome) has been publicly available before as piecemeal sequence. Beyond what it will tell the research community about yeast and about eukaryote genome organization, the yeast project has taught other sequence efforts important lessons. But many of these lessons are negative: Yeast is a model organism in the human genome project. But yeast does not provide a model for the execution, funding, and management of future genome projects.

Perhaps the most striking anomaly of the yeast project has been its overtly political overtone-what Goffeau calls its "social dimension." The project started in 1989 when a network of 37 laboratories in Europe came together under the European Commission's BAP (biomolecular action program) to sequence the smallest yeast chromosome, chromosome III. The work was completed in 1992, but the European Commission continued to fund the project under its later BRIDGE and BIOTECHNOLOGY biotechnology programs. Over half of the funding for the project came from the European Commission (Brussels), although the US National Institutes of Health (Bethesda, MD), the Wellcome Trust (London), RIKEN (Ibaraki, Japan), and McGill University (Montréal, Canada) contributed significantly. Most of the participants, especially in the earlier stages, were researchers for whom yeast-rather than sequencing-was the primary interest. The clones of various chromosome libraries were dispersed to individual laboratories, and the data collated and analyzed at the Martinsried Institute of Protein Sequences (Martinsried, Germany). The devolved mechanism was necessary politically to allow the European Commission to fund the project. And, as Goffeau points out, it contributed to "the preservation of an endangered species-the small laboratory." But there were costs, too.

The initial torpor of some data submission for chromosome III, for instance, caused the European Commission to adopt

\section{The initial torpor of some data submission for chromosome III, for instance, caused the European Commission to} adopt a pay-as-you-submit policy in later stages of the project, or as Goffeau put it, "The kinetics of submission are allosteric with a positive
effector called the Ecu."

a pay-as-you-submit policy in later stages of the project, or as Goffeau put it, "The kinetics of submission are allosteric with a positive effector called the Ecu." The dispersed approach also did little to further sequencing technology. And that, in turn, meant that the project was expensive. Goffeau estimates that the yeast genome has cost $2 \mathrm{Ecu}(\$ 2.6)$ per bp-around 25 times the expected cost of sequencing at specialist genome centers. "People say that is a lotbut a lot of things were learned along the way," said Goffeau." "It also meant that European molecular biology caught up with the United States."

Stephen Oliver from the University of Manchester Institute of Science and Technology (Manchester, UK), who coordinated the chromosome III project, recognizes-like Goffeau-that the day of the small-scale project is gone. "While it was fun (and relatively efficient)" to adopt this network approach. . .the achievements of the Sanger Center (Cambridge, UK) and the Washington University Genome Center (St. Louis, MO) demonstrate that it was not the only practical route to success."

The emphasis of yeast work in Europe, at least, will switch to functional analysis. Oliver will coordinate the EU's Ecu 7.32 million ( $\$ 9.6$ million) program in this area, EUROFAN. EUROFAN will retain the network approach, encompassing some 140 separate laboratories throughout the European Union and Switzerland. The initial aim will be a "systematic" elucidation of the biological function of the thousand or so yeast "orphan" genes to which no function has been assigned. Chris Sander and colleagues at the European BioInformatics Institute (Hinxton, UK) have already run an analysis (independent of EUROFAN) dubbed "GeneCrunch," looking at all yeast protein sequences in public databases on a Silicon Graphics supercomputer for three days at the beginning of March. While around $70 \%$ of the sequences could be assigned function by homology, and another $15 \%$ or so had homologues but no assigned function, and the rest had no homologue. But Oliver says EUROFAN will go far beyond computational analysis. "Computer analysis cannot be enough to define function. It doesn't give you biologically meaningful information."

Goffeau has practical advice for those involved in other genome projects: "All genome projects should have a good physical map first," he believes. The yeast project succeeded because of Maynard Olson's (University of Washington, Seattle) cosmid library and the libraries of the 16 individual chromosome libraries developed by Bernard Dujon at the Institute Pasteur (Paris) and Peter Phillipsen at the University of Basel (Basel, Switzerland). The current maps in Arabidopsis, C. elegans, and Drosophila are "not adequate," he says, "Neither is the human map." Goffeau also hopes that the spirit of the yeast project will remain. "People [in other genome projects] should not compete but should split up the work that has to be done."

John Hodgson 